\title{
Rectified flow in a stratified coastal ocean
}

\author{
by K. H. Brink ${ }^{1,2}$
}

\begin{abstract}
An idealized numerical model is used to explore the generation of mean flows by oscillating wind forcing in a stratified coastal ocean with no alongshore variability, i.e., where neither barotropic nor baroclinic instability is a factor. On the inner shelf, where surface-to-bottom mixing occurs, a mean cross-shelf flow develops, as examined by Castelao et al. (2010), and the present results suggest that this flow can remain two-dimensional if there is a nonzero cross-shelf density gradient. Offshore of the inner shelf, where the water column is stratified, a mean alongshore flow develops in the direction opposite to coastal-trapped wave propagation. This flow is associated with cross-shelf density gradients that are set up by the asymmetry between onshore and offshore flow in the bottom boundary layer. Both forms of rectified flow (cross-shelf and alongshore) are sensitive to the presence of surface heating, and the rectifications can be readily masked by the effect of a steady alongshore wind stress.
\end{abstract}

Keywords: Continental shelf, rectified flow, wind forcing

\section{Introduction}

Coastal oceanographers are familiar with the idea that fluctuating currents, such as tides, can generate mean alongshore and cross-shelf flow (e.g., Huthnance 1973; Loder 1980; Garrett and Loder 1981; Brink 2010). That these flows arise is not surprising because the bottom slope provides a strong and ubiquitous "topographic beta" that effectively provides a preferred alongshore direction (in the sense of long topographic Rossby wave propagation) for any steady barotropic flow.

More recently, Brink and Seo (2016) used idealized numerical models to show that fluctuating alongshore wind stresses can drive a positive (i.e., opposite to the sense of long topographic wave propagation) mean alongshore flow in a two- or three-dimensional stratified coastal ocean. In addition, Kuebel-Cervantes, Allen, and Samelson (2004) did a similar two-dimensional model run and obtained a similar mean flow, although this was not emphasized due to their concentration on Lagrangian flow patterns. This mean flow is in the opposite direction to Loder (1980)'s tidal rectification. Brink and Seo showed that when

1. Department of Physical Oceanography, Woods Hole Oceanographic Institution, Woods Hole, Massachusetts, USA.

2. Corresponding author e-mail: kbrink@whoi.edu

(C) 2018 K. H. Brink. 


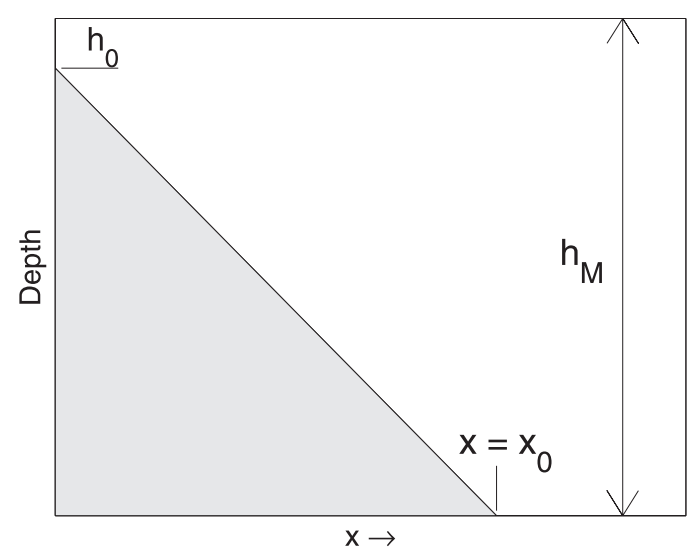

Figure 1. Schematic of the model geometry.

baroclinic instability occurs in a cyclic channel (where there is no net alongshore pressure gradient), this positive rectified flow is not destroyed. To my knowledge, there is no known example of this sort of rectified flow in nature that fits this pattern well, even though the flow is very robust in the Brink and Seo model runs. Thus, it seems reasonable to ask about the underlying dynamics of this sort of rectification, and to explore its sensitivity to forcings and to ambient conditions (e.g., stratification or bottom slope).

Another interesting rectified coastal flow is that treated by Castelao et al. (2010), who used a two-dimensional (vertical and offshore) idealized numerical model of a stratified coastal ocean to explore an Eulerian mean cross-shelf flow that occurs on the vertically well-mixed inner continental shelf. They showed that the rectified cross-shelf flows emerge both from tidal forcing and from fluctuating wind forcing. Model runs for exploring either of these rectifications (Brink and Seo vs. Castelao et al.) are the same, and so both are treated here.

The goal of the present study is to use well-resolved, idealized two-dimensional numerical models to explore both of these rectification mechanisms. Sensitivity to model parameters is considered first. The impacts of realistic complications (a surface heat flux or steady wind forcing) are then briefly explored to help understand the extent to which one might expect to observe these rectifications in the actual ocean. Finally, knowledge about the dynamics of the two rectification classes is extended by use of simple models or scaling.

\section{Model configuration}

All numerical calculations take advantage of the hydrostatic, primitive-equation Regional Ocean Modeling System (ROMS; e.g., Haidvogel et al. 2000) with a simple two-dimensional $(x, z)$ geometry (Fig. 1), where $x$ is the cross-shelf coordinate. The equations of motion are

$$
u_{t}+u u_{x}+w u_{z}-f v=-\rho_{0}^{-1} p_{x}+\left(D u_{z}\right)_{z}
$$




$$
\begin{gathered}
v_{t}+u v_{x}+w v_{z}+f u=\left(D v_{z}\right)_{z} \\
0=-p_{z}-g \rho \\
u_{x}+w_{z}=0 \\
\rho_{t}+u \rho_{x}+w \rho_{z}=\left(B \rho_{z}\right)_{z} \\
\rho=-\rho_{0} \beta\left(T-T_{0}\right)
\end{gathered}
$$

where $(u, v, w)$ are the velocity components in the $(x, y, z)$ directions, $p$ is pressure, $\rho$ is the density anomaly (relative to a constant background density $\rho_{0}=1027 \mathrm{~kg} \mathrm{~m}^{-3}$ ), $T$ is temperature, $t$ is time, $f$ is the Coriolis parameter, $g$ is the acceleration due to gravity, $\beta$ is a constant thermal expansion coefficient $\left(1.7 \times 10^{-4}{ }^{\circ} \mathrm{C}^{-1}\right)$, and $T_{0}$ is a constant reference temperature $\left(14^{\circ} \mathrm{C}\right)$. Subscripts with regard to an independent variable represent partial differentiation. The vertical turbulent mixing coefficients $B$ and $D$ (for density and momentum, respectively) are calculated using the Mellor-Yamada level 2.5 turbulence closure scheme (e.g., Wijesekera, Allen, and Newberger 2003) and are initialized at molecular levels in a resting ocean. There is no explicit lateral mixing or dissipation.

The model is forced by an alongshore wind stress of the form

$$
\tau^{y}=R(t) \tau_{0}+\tau_{A} \sin \left(2 \pi t \Omega_{w}^{-1}\right)
$$

where $\Omega_{w}$ is the wind forcing period and $R(t)$ is a smooth ramp-up function

$$
\begin{array}{ll}
R(t)=0.5\left[1-\cos \left(\pi t t_{R}^{-1}\right)\right] & \text { for } t<t_{R}, \\
R(t)=1 & \text { for } t>t_{R}
\end{array}
$$

and $t_{R}=1$ day unless otherwise stated. In addition, a steady, spatially uniform surface heat flux $Q$ is sometimes imposed so that

$$
B T_{z}=Q\left(\rho_{0} C_{p}\right)^{-1} \quad \text { at } z=0
$$

where $C_{p}$ is the heat capacity $\left(4.00 \times 10^{3} \mathrm{~J}\left(\mathrm{Kg}^{\circ} \mathrm{C}\right)^{-1}\right)$. The bottom stress $\boldsymbol{\tau}_{\boldsymbol{B}}$ is given by

$$
\tau_{\boldsymbol{B}}=\rho_{0} r v_{B}
$$

where the resistance parameter $r$ is constant in space and the subscript B denotes a variable evaluated at the grid point closest to the bottom.

The model geometry (Fig. 1) is given by simply

$$
\begin{array}{ll}
h=h_{0}+\alpha x & \text { for } x<x_{0} \\
h=h_{0}+\alpha x_{0} \equiv h_{M} & \text { for } x>x_{0}
\end{array}
$$

where $h_{0}=5 \mathrm{~m}, x_{0}=45 \mathrm{~km}$, and $h_{M}$ is the constant water depth far offshore. The model grid extends $55 \mathrm{~km}$ offshore. It has a variable horizontal resolution of $0.15-0.25 \mathrm{~km}$ (finer 
in shallow water), and 70 vertical grid points distributed so as to maximize resolution in the surface and bottom boundary layers.

The model has a free-slip wall at $x=0$ and an open boundary at $x=x_{M}$. The open boundary conditions call for no normal gradient for temperature and depth-dependent velocity, and the boundary condition for the free surface height (tidal variations) is

$$
\zeta=\zeta_{0} \sin \left(2 \pi t \Omega_{p}^{-1}\right)
$$

where $\Omega_{p}$ is the forcing period for sea level height. Initially, the ocean is at rest and has a uniform vertical temperature gradient $T_{z 0}$.

A total of fifty-two 100-day model runs were initially conducted. In most cases, $\zeta_{0}=$ $Q=\tau_{0}=0$, and emphasis is placed on varying $T_{z 0}, f, \alpha, \tau_{A}, \Omega_{w}$, and $r$ (Table 1). Time means are computed over a 20-day interval beginning on day 78 and are denoted by $<q>$, whereas fluctuations are denoted by $q^{\prime}=q-<q>$. Throughout the following, 20 days will be the standard averaging interval because this is an even multiple of all forcing periods used.

\section{Numerical results}

\section{a. Averaged sections}

Results from a representative model run (number 4), averaged over a 20-day period beginning with day 78, are show in Figure 2. For this run, the wind amplitude $\left(\tau_{A}=0.05\right.$ $\mathrm{N} \mathrm{m}^{-2}$ ), wind period (5 days), bottom slope (0.00233), and Coriolis parameter $\left(1 \times 10^{-4}\right.$ $\left.\mathrm{sec}^{-1}\right)$ have representative values, but initial stratification $\left(T_{z 0}=0.06{ }^{\circ} \mathrm{C} \mathrm{m}^{-1}\right)$ is larger than for most runs. Over most of the domain shown, the time mean alongshore flow is positive (in the sense opposite to coastal-trapped wave propagation), with a peak value (denoted as $v_{\text {Max }}$ ) of about $0.03 \mathrm{~m} \mathrm{sec}^{-1}$ near the offshore edge of the nearshore wellmixed region. (For clarity: $v_{\text {Max }}$ is the spatial maximum of $\langle v\rangle$, the time-averaged mean alongshore flow). In addition, there are weaker negative mean alongshore flows within the well-mixed inner shelf (this extremum is denoted as $v_{S}$ ) and in the bottom boundary layer. The temperature structure is characterized by a $25-\mathrm{m}$ surface mixed layer, and by upwarped isotherms near the bottom boundary. This near-bottom structure is qualitatively consistent, through a thermal wind balance, with the overlying mean alongshore interior flow. The coldest surface waters are found around $x=7 \mathrm{~km}$, so that temperature decreases offshore over the innermost shelf. This offshore temperature minimum was also found for fluctuating winds by Castelao et al. (2010) and for steady upwelling-favorable winds by Austin and Lentz (2002). The offshore decrease is qualitatively consistent with the temperature gradient that would be formed by simply vertically mixing the water column over a sloping bottom. This idea is, in fact, a good approximation when $\tau_{A}<0$, but, when $\tau_{A}>0$, the gradient is augmented by upwelling during the first half cycle of the wind forcing. Other aspects of the model results, especially the magnitude of the positive mean alongshore flow, differ when the sign of $\tau_{A}$ becomes negative (e.g., comparing run 4 with run 34 in Table 1). This 
Table 1. Summary of numerical model runs

\begin{tabular}{|c|c|c|c|c|c|c|c|c|c|c|c|}
\hline Run & $\begin{array}{c}T_{z 0} \\
{ }^{\circ} \mathrm{m}^{-1}\end{array}$ & $\begin{array}{c}\tau_{A} \\
\mathrm{~N} \mathrm{~m}^{-2}\end{array}$ & $\begin{array}{c}\tau_{0} \\
\mathrm{~N} \mathrm{~m}^{-2}\end{array}$ & $\begin{array}{c}\Omega_{W} \\
\text { days }\end{array}$ & $\alpha$ & $\begin{array}{c}f \times 10^{4} \\
\sec ^{-1}\end{array}$ & $\begin{array}{l}r \times 10^{4} \\
\mathrm{~m} \mathrm{sec}^{-1}\end{array}$ & $\zeta_{A}$ & $\begin{array}{c}Q /\left(\rho_{0} C_{p}\right) \times 10^{5} \\
{ }^{\circ} \mathrm{m} \mathrm{sec}^{-1}\end{array}$ & $\begin{array}{c}\psi_{S} \\
\mathrm{~m}^{2} \sec ^{-1}\end{array}$ & $\begin{array}{c}v_{\operatorname{Max}} \\
\mathrm{m} \mathrm{sec}^{-1}\end{array}$ \\
\hline 1 & 0.03 & 0.05 & 0.0 & 5.0 & 0.0023 & 1 & 5 & 0 & 0 & -0.036 & 0.015 \\
\hline 2 & 0.003 & 0.05 & 0.0 & 5.0 & 0.0023 & 1 & 5 & 0 & 0 & -0.012 & 0.001 \\
\hline 3 & 0.03 & -0.05 & 0.0 & 5.0 & 0.0023 & 1 & 5 & 0 & 0 & -0.044 & 0.002 \\
\hline 4 & 0.06 & 0.05 & 0.0 & 5.0 & 0.0023 & 1 & 5 & 0 & 0 & -0.032 & 0.034 \\
\hline 5 & 0.015 & 0.05 & 0.0 & 5.0 & 0.0023 & 1 & 5 & 0 & 0 & -0.031 & 0.005 \\
\hline 6 & 0.03 & 0.05 & 0.0 & 5.0 & 0.0023 & 1 & 1 & 0 & 0 & -0.021 & 0.013 \\
\hline 7 & 0.03 & 0.05 & 0.0 & 5.0 & 0.0023 & 1 & 10 & 0 & 0 & -0.041 & 0.014 \\
\hline 8 & 0.03 & 0.05 & 0.0 & 5.0 & 0.0023 & 0.5 & 5 & 0 & 0 & -0.063 & 0.029 \\
\hline 9 & 0.03 & 0.05 & 0.0 & 5.0 & 0.0023 & 0.25 & 5 & 0 & 0 & -0.145 & 0.032 \\
\hline 10 & 0.03 & 0.05 & 0.0 & 5.0 & 0.0039 & 1 & 5 & 0 & 0 & -0.019 & 0.038 \\
\hline 11 & 0.03 & 0.05 & 0.0 & 5.0 & 0.0012 & 1 & 5 & 0 & 0 & -0.034 & 0.004 \\
\hline 12 & 0.03 & 0.10 & 0.0 & 5.0 & 0.0023 & 1 & 5 & 0 & 0 & -0.068 & 0.023 \\
\hline 13 & 0.03 & 0.025 & 0.0 & 5.0 & 0.0023 & 1 & 5 & 0 & 0 & -0.019 & 0.009 \\
\hline 14 & 0.03 & 0.05 & 0.0 & 10.0 & 0.0023 & 1 & 5 & 0 & 0 & -0.027 & 0.026 \\
\hline 15 & 0.03 & 0.05 & 0.0 & 20.0 & 0.0023 & 1 & 5 & 0 & 0 & -0.005 & 0.029 \\
\hline 16 & 0.03 & 0.05 & 0.0 & 5.0 & 0.0039 & 1 & 5 & 0 & 0 & -0.029 & 0.052 \\
\hline 17 & 0.06 & 0.05 & 0.0 & 5.0 & 0.0039 & 0.5 & 5 & 0 & 0 & -0.019 & 0.073 \\
\hline 18 & 0.015 & 0.05 & 0.0 & 5.0 & 0.0012 & 0.5 & 5 & 0 & 0 & -0.024 & 0.002 \\
\hline 19 & 0.03 & 0.05 & 0.0 & 10.0 & 0.0012 & 1 & 5 & 0 & 0 & -0.004 & 0.006 \\
\hline 20 & 0.03 & 0.05 & 0.0 & 10.0 & 0.0039 & 1 & 5 & 0 & 0 & -0.005 & 0.062 \\
\hline 21 & 0.06 & 0.02 & 0.0 & 20.0 & 0.0023 & 0.5 & 2 & 0 & 0 & -0.002 & 0.097 \\
\hline 22 & 0.06 & -0.05 & 0.0 & 5.0 & 0.0039 & 0.5 & 5 & 0 & 0 & -0.048 & 0.037 \\
\hline 23 & 0.06 & -0.02 & 0.0 & 20.0 & 0.0023 & 0.5 & 2 & 0 & 0 & -0.001 & 0.065 \\
\hline 24 & 0.03 & -0.05 & 0.0 & 5.0 & 0.0039 & 1 & 5 & 0 & 0 & -0.013 & 0.034 \\
\hline 25 & 0.03 & 0.05 & 0.0 & 20.0 & 0.0023 & 2 & 5 & 0 & 0 & -0.005 & 0.008 \\
\hline 26 & 0.03 & -0.05 & 0.0 & 5.0 & 0.0023 & 1 & 1 & 0 & 0 & - & 0.004 \\
\hline 27 & 0.03 & -0.05 & 0.0 & 5.0 & 0.0039 & 1 & 5 & 0 & 0 & -0.032 & 0.019 \\
\hline 28 & 0.03 & -0.05 & 0.0 & 5.0 & 0.0023 & 0.5 & 5 & 0 & 0 & -0.086 & 0.007 \\
\hline 29 & 0.03 & -0.05 & 0.0 & 20.0 & 0.0023 & 1 & 5 & 0 & 0 & -0.026 & 0.014 \\
\hline 30 & 0.03 & -0.05 & 0.0 & 20.0 & 0.0023 & 2 & 5 & 0 & 0 & -0.011 & 0.002 \\
\hline 31 & 0.03 & -0.05 & 0.0 & 5.0 & 0.0012 & 1 & 5 & 0 & 0 & -0.040 & - \\
\hline 32 & 0.03 & -0.05 & 0.0 & 10.0 & 0.0023 & 1 & 5 & 0 & 0 & -0.045 & 0.008 \\
\hline 33 & 0.03 & -0.10 & 0.0 & 5.0 & 0.0023 & 1 & 5 & 0 & 0 & -0.082 & 0.004 \\
\hline 34 & 0.06 & -0.05 & 0.0 & 5.0 & 0.0023 & 1 & 5 & 0 & 0 & -0.045 & 0.014 \\
\hline 35 & 0.03 & 0.05 & 0.0 & 2.0 & 0.0023 & 1 & 5 & 0 & 0 & -0.025 & 0.005 \\
\hline 36 & 0.03 & 0.05 & 0.01 & 5.0 & 0.0023 & 1 & 5 & 0 & 0 & - & 0.197 \\
\hline 37 & 0.03 & 0.05 & 0.001 & 5.0 & 0.0023 & 1 & 5 & 0 & 0 & -0.042 & 0.040 \\
\hline 38 & 0.03 & 0.05 & -0.001 & 5.0 & 0.0023 & 1 & 5 & 0 & 0 & -0.011 & - \\
\hline 39 & 0.06 & 0.02 & -0.002 & 20.0 & 0.0023 & 0.5 & 2 & 0 & 0 & - & 0.014 \\
\hline 40 & 0.06 & 0.02 & -0.0025 & 20.0 & 0.0023 & 0.5 & 2 & 0 & 0 & - & 0.004 \\
\hline 41 & 0.03 & 0.0 & 0.0 & - & 0.0023 & 1 & 5 & $2.0^{*}$ & 0 & -0.005 & 0.005 \\
\hline 42 & 0.03 & 0.05 & 0.0 & 5.0 & 0.0023 & 1 & 5 & $2.0^{*}$ & 0 & -0.040 & 0.004 \\
\hline 43 & 0.03 & 0.05 & 0.0 & 10.0 & 0.0023 & 1 & 5 & $2.0^{*}$ & 0 & -0.043 & 0.004 \\
\hline 44 & 0.03 & 0.0 & 0.0 & - & 0.0023 & 1 & 5 & $0.1^{\dagger}$ & 0 & -0.0002 & - \\
\hline 45 & 0.003 & 0.0 & 0.0 & - & 0.0023 & 1 & 5 & $0.1^{\dagger}$ & 0 & -0.0000 & - \\
\hline 46 & 0.03 & 0.05 & 0.0 & 5.0 & 0.0023 & 1 & 5 & $1.0^{*}$ & 0 & -0.004 & 0.007 \\
\hline 47 & 0.06 & 0.02 & 0.0 & 20.0 & 0.0023 & 0.5 & 2 & $1.0^{*}$ & 0 & -0.056 & 0.094 \\
\hline 48 & 0.03 & 0.05 & 0.0 & 5.0 & 0.0023 & 1 & 5 & 0.0 & -2 & - & 0.174 \\
\hline 49 & 0.03 & 0.05 & 0.0 & 5.0 & 0.0023 & 1 & 5 & 0.0 & +2 & -0.007 & 0.124 \\
\hline 50 & 0.03 & 0.05 & 0.0 & 5.0 & 0.0023 & 1 & 5 & 0.0 & -7 & - & 0.548 \\
\hline 51 & 0.03 & -0.05 & 0.0 & 5.0 & 0.0023 & 1 & 5 & 0.0 & -2 & - & 0.172 \\
\hline 52 & 0.03 & -0.05 & 0.0 & 5.0 & 0.0023 & 1 & 5 & 0.0 & +2 & -0.005 & 0.125 \\
\hline
\end{tabular}

* Sea level forcing period of 0.5 days.

${ }^{\dagger}$ Sea level forcing period of 5.0 days. 

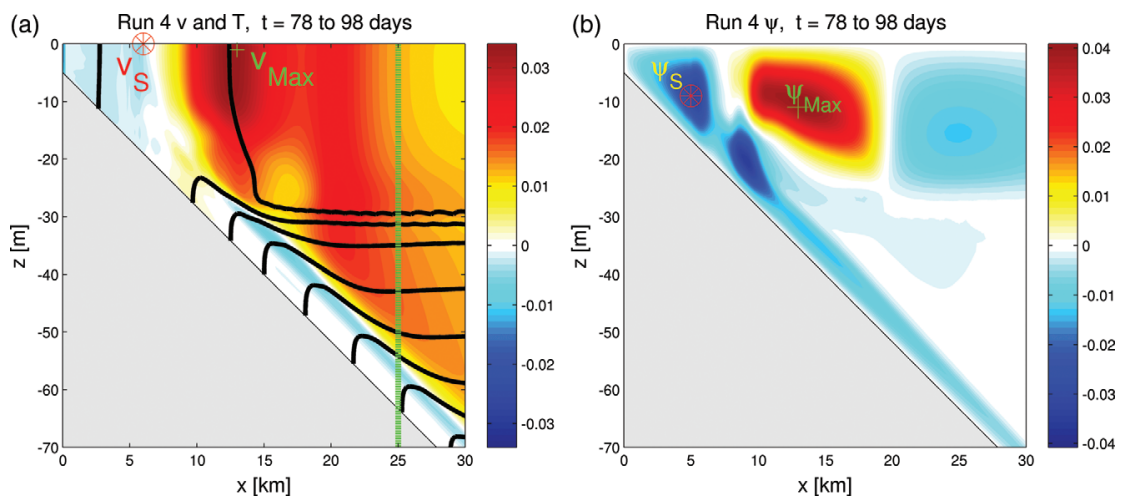

Figure 2. Mean conditions from model run 4, averaged over days 78-98. a) Mean alongshore velocity (color: $\mathrm{m} \mathrm{sec}^{-1}$ ) and temperature (contour interval $=0.5^{\circ} \mathrm{C}$ ). The vertical green line at $x=25 \mathrm{~km}$ denotes the position where mean profiles are computed (Fig. 4). b) Mean stream function with positive values corresponding to counterclockwise circulation as viewed in this plane. Only the inner $30 \mathrm{~km}$ are shown.

discrepancy will be argued (below) to be an artificiality associated with the model having well-defined initial conditions and responses that are too idealized in the realistic context where forcing has been active indefinitely.

The mean cross-shelf/vertical flow field is summarized by means of a stream function defined by

$$
\psi=\int_{-h}^{z} u d z
$$

so that positive extremes correspond to a circulation that is counterclockwise as viewed in Figure $2 b$. In most cases, including this one, there is a negative $\langle\psi\rangle$ extremum nearshore (extreme value denoted as $\psi_{S}$ ) corresponding to offshore flow near the surface, and onshore at depth. Associated with this cross-shelf flow, there is often a negative extremum of alongshore flow $\left(v_{S}\right)$, i.e., in the sense of traditional rectification mechanisms such as Loder's. This extremum typically falls at the offshore boundary of the well-mixed inner shelf for runs $1-35$. Farther offshore, associated with the maximum $\left\langle v>\right.$, there is a maximum $\psi_{\text {Max }}$ corresponding to onshore flow near the surface. In addition, there are negative $\langle\psi\rangle$ extrema offshore near the surface (near $x=24 \mathrm{~km}, z=-15 \mathrm{~m}$ in Fig. 2b) and within the bottom boundary layer (near $x=10 \mathrm{~km}, z=-20 \mathrm{~m}$ in Fig. 2b). These two features both occur entirely within their respective turbulent boundary layers (Figs. 2 and 3; the bottom boundary layer is roughly defined by vertically homogeneous waters or by blue-negative alongshore velocity - and white colors in Fig. 2a), so that the net mean Eulerian cross-shelf transport in both of these boundary layers is approximately zero. In the bottom boundary layer, this two-way flow pattern is consistent with ideas about flow driven by boundary mixing (e.g., Phillips, Shyu, and Salmun 1986; Garrett, MacCready, and Rhines 1993). A high 


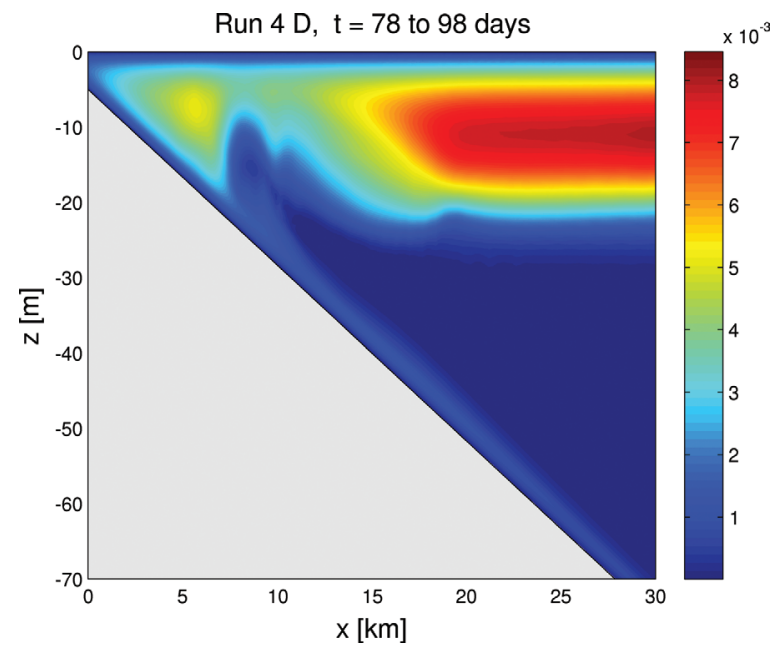

Figure 3. Mean turbulent eddy viscosity $\left(\mathrm{m}^{2} \mathrm{sec}^{-1}\right)$ for run 4 , days 78 to 98 . Only the inner $30 \mathrm{~km}$ are shown.

degree of turbulence (as expressed by the eddy viscosity $D$; Fig. 3) is maintained by the energetic fluctuating flow, even though the mean flows are relatively weak (For example, with run 4 at $x=13 \mathrm{~km}$, the amplitude of alongshore velocity fluctuations is $0.09 \mathrm{~m} / \mathrm{sec}$, whereas the maximum mean alongshore velocity is $\left.0.034 \mathrm{~m} \mathrm{sec}^{-1}\right)$.

The extrema defined above $\left(v_{S}, v_{\operatorname{Max}}, \psi_{S}\right.$, and $\left.\psi_{\text {Max }}\right)$ are identifiable in nearly all model runs that do not include a mean wind stress or surface heat flux. In some cases, for example involving an adverse steady wind stress $\tau_{0}$ (e.g., runs 36 or 38), a mean alongshore flow pattern will vanish (e.g., when $\tau_{0}>0$, there may not be a negative $v_{S}$ ), in which case, the missing positive or negative extreme is denoted by a blank in Table 1 . The magnitude of Castelao et al. (2010)'s rectified cross-shelf flow is identified with $\psi_{S}$ and the positive alongshore current rectification identified by Brink and Seo (2016) is identified with $v_{\operatorname{Max}}$. Occasionally, the bottom boundary layer $\langle\psi\rangle$ minimum merges with the nearshore minimum, but this is usually not the case.

\section{b. Momentum fluxes and vertical mixing}

In a steady state, the total (mean plus eddy) depth-integrated cross-shelf transport of momentum ought to balance the cross-shelf integrated mean bottom frictional drag inshore of a given line. For example, the cross-shelf flux of alongshore momentum is calculated at $x=25 \mathrm{~km}$ (far enough offshore to have distinct surface and bottom boundary layers) for run 4 (Fig. 4). The momentum flux is completely dominated by the eddy component, i.e., the flux due to mean flow $\langle u\rangle\langle v\rangle$ is negligible. Near the surface, the momentum flux is offshore (positive), whereas, near the bottom, the flux is onshore. The net offshore 


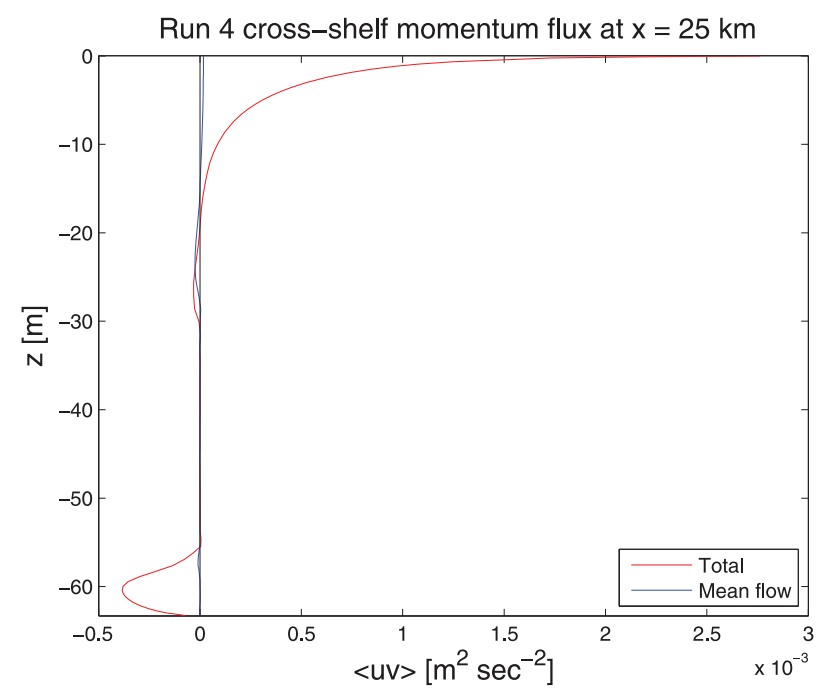

Figure 4. Mean (days 78-98) cross-shelf flux of alongshore momentum for run 4 at $x=25 \mathrm{~km}$.

The contribution of mean flow is shown in blue (and is very weak), and the contribution of total flow (mean plus fluctuating) is shown in red.

momentum flux is then compensated by the bottom stress associated with a negative nearbottom alongshore flow (e.g., Fig. 2). Note that this negative $\langle v\rangle$, which is in the sense of coastal-trapped wave propagation, is confined to the inner shelf and the bottom boundary layer. Typically, however, for runs with no mean wind stress or surface heat flux, most of the shelf offshore of the inner shelf and above the bottom boundary layer is dominated by positive $<v>$, i.e., opposite to the sense of topographic Rossby wave propagation.

It is useful to define a criterion for the width of the inner shelf region. Because the inner shelf is considered to be the highly turbulent region where waters are relatively well-mixed vertically, it seems sensible to define the inner shelf boundary in terms of where turbulent mixing becomes sufficiently small. Because the turbulence closure scheme depends strongly on the gradient Richardson number $\left(\mathrm{Ri}=N^{2}\left|v_{z}^{2}\right|^{-1}\right.$, computed here-for numerical stability-by averaging $N^{2}=-g \rho_{z} \rho_{0}^{-1}$ and $\left|v_{z}^{2}\right|$ separately and then taking the ratio) for setting the vertical mixing coefficients, the present approach calls for finding the most onshore location $x_{I S}$ where the time-average Richardson number is greater than a threshold value somewhere in the water column ( $\mathrm{Ri}=10$ is large enough to ensure a consistent shut-down of turbulent mixing through an entire wind cycle). The inner shelf boundary is then, for example, $13.4 \mathrm{~km}$ for run 4 in Figure 2a. Although the inner shelf is vertically well-mixed for either sign of $\tau_{A}$, there is only initially a substantial offshore heat flux from the inner shelf region when $\tau_{A}>0$ (initial upwelling) and a much weaker one when there is downwelling initially. This contrast is consistent with the notion that conditions are relatively stagnant inshore of a downwelling front (e.g., Allen and Newberger 1996). 
Far from the coast, the near-surface fields have relatively weak offshore gradients (e.g., Figs. 2 and 3 show that gradients have already weakened substantially by $x=30 \mathrm{~km}$ ). One would thus expect that surface mixed-layer physics would be one-dimensional at this distance offshore (i.e., that lateral advection is not important near the surface), and this is indeed the case. At $x=40 \mathrm{~km}$, the day 78-98 average mixed layer depth is wellparameterized by the Pollard-Rhines-Thompson depth (Pollard, Rhines, and Thompson 1973)

$$
\delta=\frac{a_{1} u^{*}}{\sqrt{f N_{0}}}
$$

where (based on least-squares fit using 39 model runs with $Q=\tau_{M}=0$ ) $a_{1}=3.8, N_{0}$ is the initial buoyancy frequency, and $u^{*}=\left(\left|\tau_{A}\right| \rho_{0}^{-1}\right)^{1 / 2}$. The correlation of the fit is 0.99 and the rms error in $\delta$ is $2 \mathrm{~m}$. If the calculation is repeated using $\delta$ calculated for days 478-498, the regression coefficient $a_{1}$ is $37 \%$ larger, presumably reflecting continued slow erosion of the mixed layer base in the presence of continued fluctuating wind forcing.

\section{c. Temporal adjustment}

As in Brink and Seo (2016), the model adjustment is very dependent on the initial phase of the wind forcing (Fig. 5, black lines). When $\tau_{A}>0$ (run 1), the initial winds are upwelling favorable, the initial maximum alongshore surface velocity (averaged over 20day increments) occurs at about $x=10 \mathrm{~km}$, and the maximum slowly drifts offshore to $x=20 \mathrm{~km}$ by day 500 . By day 30 , the maximum surface mean velocity is about $0.015 \mathrm{~m} \mathrm{sec}$, and it then slowly decelerates to $0.01 \mathrm{~m} \mathrm{sec}^{-1}$ by day 500 . For an identical run, but with $\tau_{A}<0$ (downwelling initially; run 3, black dashed lines), there is initially no positive mean alongshore surface flow anywhere, and, although the flow seems to be adjusting toward the same position and peak velocity as for run 1, the maximum alongshore flow still only reaches $0.005 \mathrm{~m} \mathrm{sec}^{-1}$ by day 500 . Inspection of the time-averaged temperature field for an intermediate time (Fig. 6) sheds some light on the adjustment. The temperature fields in the bottom boundary layer are strikingly different. The differences can be explained in light of the time evolution and notions about the dependence of boundary layer thickness on whether flow is upslope or downslope (e.g., Brink and Lentz 2010a). For run 1, there was initially a strong upslope penetration in a relatively thin bottom boundary layer, followed by a weaker downslope flow in a thick bottom boundary layer (see also Figure 2 in Brink and Seo 2016 for illustrative snapshots of the temperature field). The initial upslope penetration was not entirely neutralized in subsequent forcing cycles. In contrast, when the initial bottom boundary layer flow is downslope (Run 3), there is initially a slow downslope flow in a thick bottom boundary layer, but the subsequent upslope flow also takes place in a relatively thick layer, so that the subsequent upslope penetration is not as substantial as when $\tau_{A}>0$ (see Figure 3 in Brink and Seo 2016). A steady state independent of initial conditions is eventually expected for times longer than 500 days, but whether such a state is meaningful, given variability in the real ocean, is questionable. For this reason, analysis 

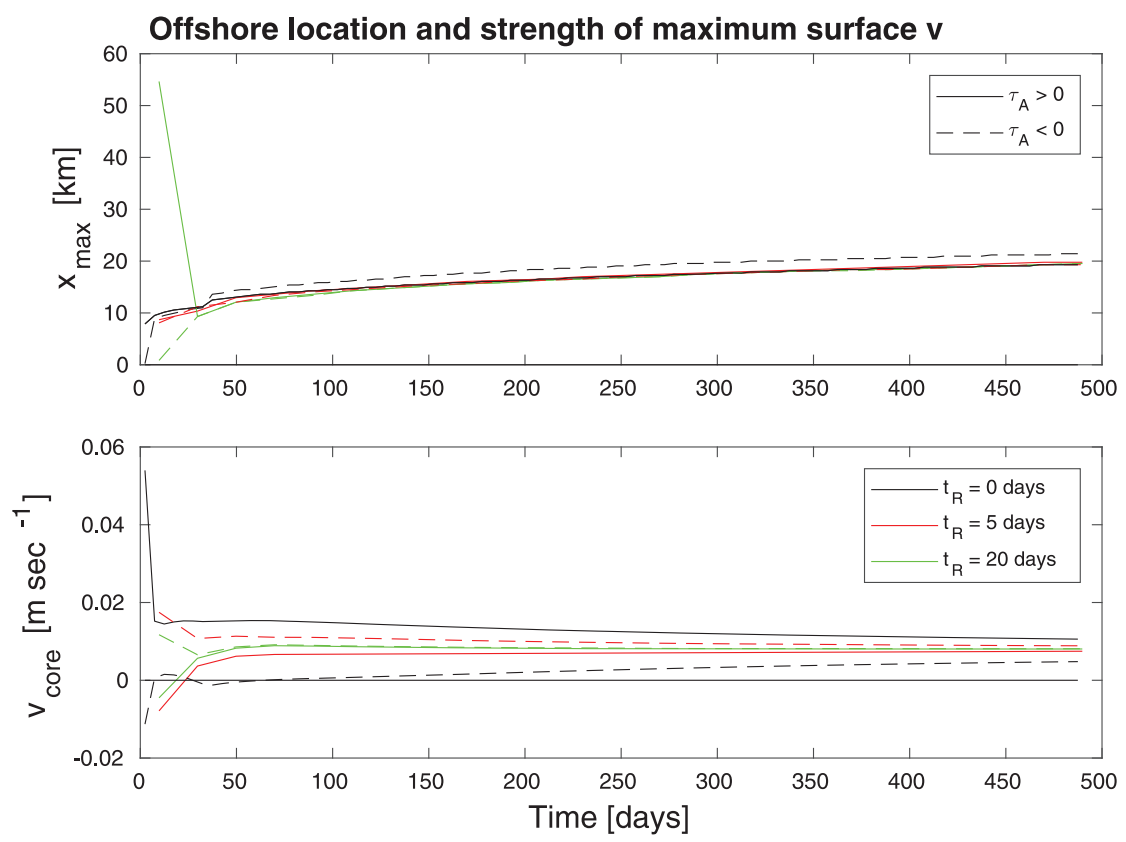

Figure 5. Upper panel: offshore position $x_{\max }$ of the maximum surface alongshore velocity (averaged over 20-day segments) as a function of time for runs with $\tau_{A}>0$ (solid lines) and for $\tau_{A}<0$ (dashed lines). The colors correspond to runs 1 and 3 (black), and the same runs but with a ramp time of 5 days (red) and 20 days (green). Lower panel: maximum 20-day mean alongshore velocity (at $x=x_{\max }$ ) as a function of time, using the same line conventions.

here is restricted to $t<100$ days, even though a steady state for $v_{\text {Max }}$ has not generally been established.

It is important to point out the sense in which the differences related to the sign of $\tau_{A}$ are artificial. The asymmetry is associated with the fact that initial isotherms are flat, and that the initial flow is either strong upwelling or slower downwelling in the bottom boundary layer. In the real ocean, well-defined, tidy initial conditions are a rarity, and a simply defined wind stress variability is rarely switched on. Consistent with this notion, as will be seen below, adding more elements of realism (such as a time-mean wind stress or a surface heat flux) decreases the asymmetry. Another test (suggested by a helpful reviewer) is simply to apply the ramp function (Eqs. $2 \mathrm{~b}$ and c) to the sinusoidal component of wind stress and then repeat the calculations represented by runs 1 and 3 . This ought to reduce the dependence on initial response and so demonstrate the artificiality of the asymmetry. The results are shown as the red (5-day ramp time) and green (20-day ramp time) curves in Figure 5. Indeed, with a 5-day ramp, the discrepancy is lessened, and with a 20-day ramp, the discrepancy is eliminated for $t>60$ days. For the 20-day ramp run, $v_{\text {Max }}$ converges to a value in between those for runs 1 and 3. Therefore, although the differing results for runs with positive and negative 


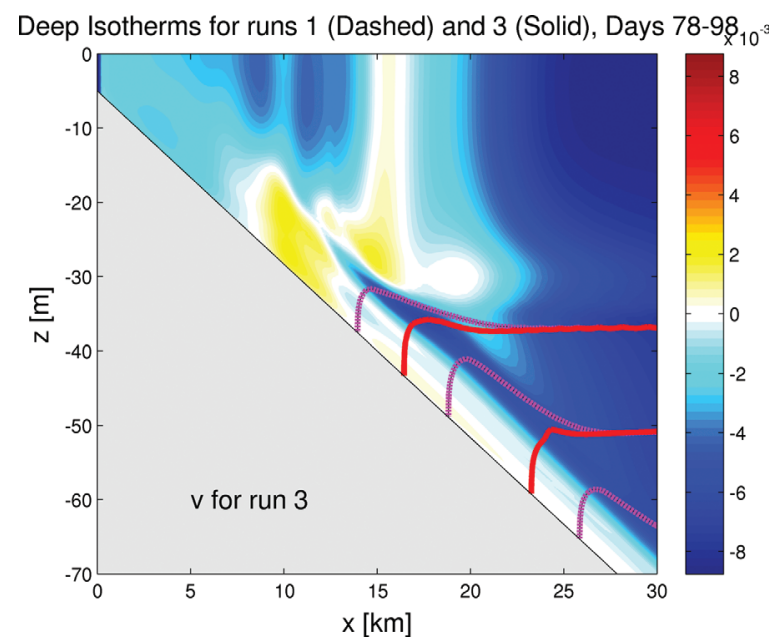

Figure 6. Selected deep isotherms of mean temperature for days 78-98 (contours: $0.5^{\circ}$ interval) for run 1 ( $\tau_{A}>0$ : dotted magenta) and run 3 (identical to 1 but $\tau_{A}<0$ : solid red). The mean along-channel velocity $\left(\mathrm{m} \mathrm{sec}^{-1}\right)$ for run 3 is shown in color. Only the inner $30 \mathrm{~km}$ are shown and shallower isotherms (which differ between the two runs) are not shown in order to emphasize the bottom boundary layer structures.

initial forcing are treated separately here, it should be kept in mind that the differing results are an artifact, and the truth should be taken to lie between. It is nonetheless remarkable that the effects of the initial response can endure for hundreds of days in a coastal (shallow water) context where one might expect that dissipative effects would erase "memory" after a few tens of days.

Returning to the examples with no ramp function, and consistent with the mean alongshore flow being in thermal wind balance, positive interior flow appears within days in the $\tau_{A}>0$ cases, where the bottom boundary quickly develops strong lateral density gradients. For the $\tau_{A}<0$ cases, the bottom boundary layer horizontal density gradient (tied to upslope phase of penetration) only appears over longer time scales (hundreds of days), and mean alongshore flow is similarly slow to develop. Over these longer time scales, the bottom boundary layers in the two cases seem to converge toward similar structures, and the interior flow fields do as well. Thus, because of the different initial responses, the results averaged over days 78-98 are artificially divergent for different signs of initial forcing. The following analysis is therefore carried out separately for the two forcing signs. An alternative would be to carry out all runs for extremely long, $O(1,000$ days $)$, times, but then one would have to question how applicable the results would be to the real ocean, where nontidal forcing is rarely stationary over such a long time. A second alternative, of course, is to use a ramp function $(2 \mathrm{~b}, \mathrm{c})$ with all model runs, and this is discussed in section 5 (below). 

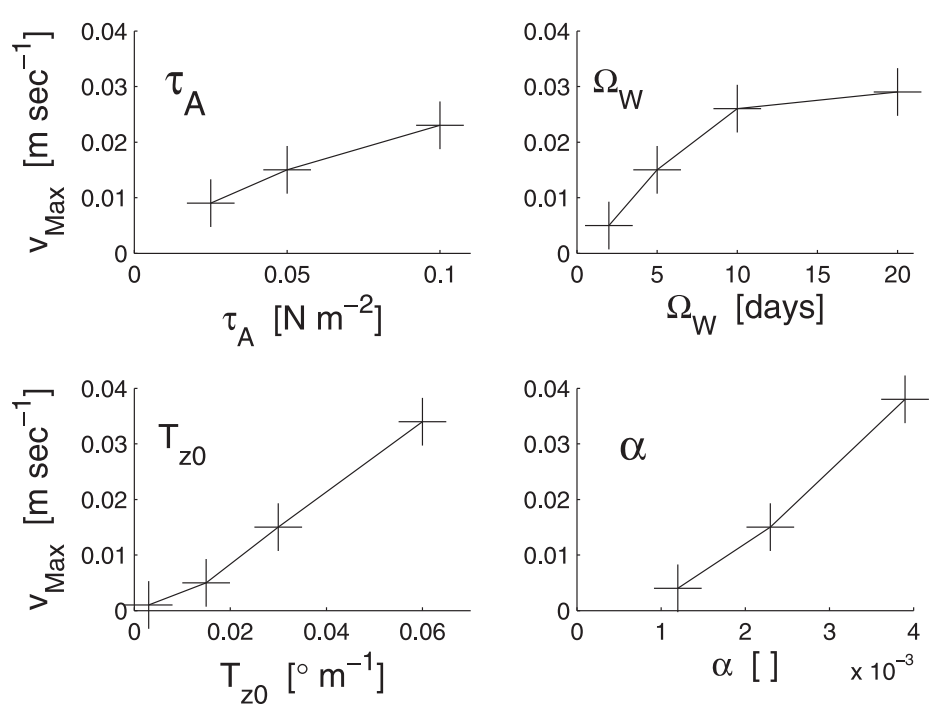

Figure 7. Dependence of maximum alongshore velocity (averaged over days 78-98) on input parameters: wind stress amplitude $\tau_{A}$ (runs 13,1, and 12), wind forcing period $\Omega_{W}$ (runs $35,1,14$, and 15), initial vertical temperature gradient $T_{z 0}$ (runs $2,5,1$, and 4), and bottom slope $\alpha$ (runs 11, 1 , and 10).

\section{d. Qualitative trends for 78-98 day means}

As already noted, the different temporal adjustments lead to initially downwelling $\left(\tau_{A}<0\right)$ runs always having weaker (compared with initially upwelling cases) positive mean alongshore flow $v_{\text {Max }}$ at a given time (Table 1). However, on the inner shelf, the rectified upwelling cell (as indicated by negative $\psi_{S}$ ) always sets up relatively quickly. Even so, the sign of $\tau_{A}$ remains somewhat important: runs with $\tau_{A}<0$ produce nearshore circulations comparable with or stronger than for cases with $\tau_{A}>0$ (e.g., compare runs 1 to 3,4 to 34,15 to 29 , or 21 to 23 ). As will be seen below, the nearshore circulation is sensitive to the local horizontal density gradient, and so differences related to the sign of $\tau_{A}$ (hence initial upwelling vs. downwelling, which lead to differing initial inner shelf heat transport) are not unexpected.

The maximum mean alongshore flow $v_{\text {Max }}$ (Fig. 7) increases with increasing fluctuating wind stress amplitude (runs 13 vs. 1 vs. 12), and with forcing period $\Omega_{W}$ (runs 35 vs. 1 vs. 14 vs. 15). Also, $v_{\operatorname{Max}}$ increases with initial stratification $T_{z 0}$ (runs 2, 5, 1, and 4) and bottom slope $\alpha$ (runs 11,1, and 10). Maximum mean flow weakens as the rotation rate $f$ increases (runs 9, 8, and 1), and is not obviously dependent on the strength of bottom friction $r$ (runs 6,1 , and 7). These patterns are rationalized in section 5 (below).

The strength of the nearshore upwelling cell $\psi_{S}$ also increases with the wind-forcing amplitude $\tau_{A}$ (runs 13, 1, and 12) and with the strength of bottom friction $r$ (runs 6, 1, 

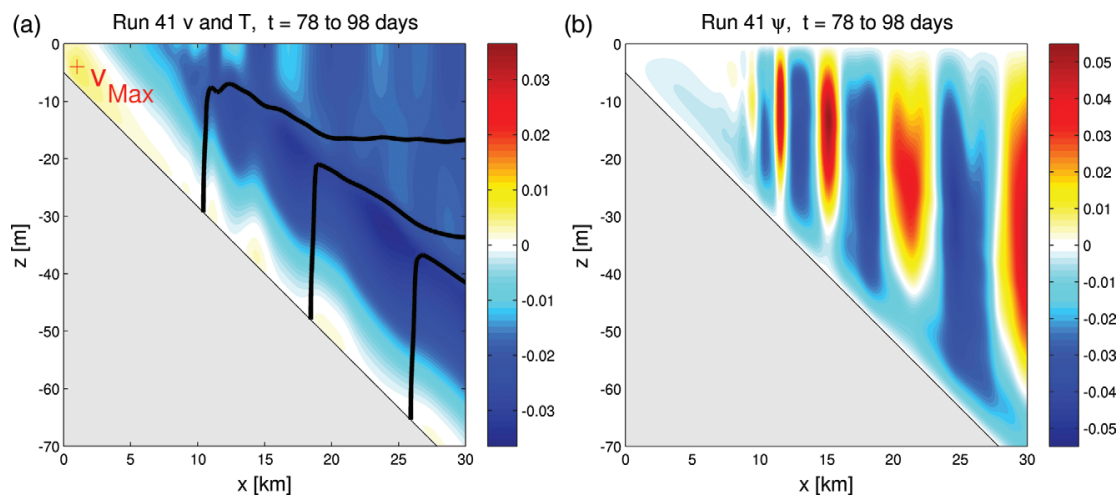

Figure 8. Results, averaged over 20 days, beginning with $t=78$ days, for run 41 with superinertial "tidal" forcing. a: mean alongshore velocity (color) and temperature $\left(0.5^{\circ}\right.$ contour interval). b: streamfunction $\left(\mathrm{m}^{2} \mathrm{sec}^{-1}\right)$.

and 7). The nearshore upwelling decreases with the Coriolis parameter $f$ (runs 9,8 , and 1), but the patterns of sensitivity are not obvious with regard to forcing period, initial stratification, or bottom slope.

A run forced only by superinertial offshore sea level fluctuations ("tides"; run 41) gives rise to complex, multibanded cross-shelf/vertical mean circulations over the shelf topography (Fig. 8b), but the mean alongshore flow is spatially smooth and negative almost everywhere (Fig. 8a). This predominant alongshore flow is, in a sense, expected based on traditional ideas about tidal rectification (e.g., Loder 1980), but the relatively complex cross-shelf flow is evidently associated with internal wave phenomena that are not present in, for example, Loder's barotropic model. For offshore forcing at subinertial frequencies (runs 44 and 45), the mean cross-shelf circulation is bottom-intensified and has a much less complex structure. These subinertial runs again have spatially smooth negative alongshore mean flows, but they are far weaker than in the superinertial case $\left(>-0.0003 \mathrm{~m} \mathrm{sec}^{-1} \mathrm{vs}\right.$. $-0.036 \mathrm{~m} \mathrm{sec}^{-1}$ ), presumably reflecting the Taylor-Proudman resistance to the fluctuating flow crossing topography, hence an ineffective cross-shelf momentum flux. Superimposing "tidal" forcing on fluctuating wind forcing (e.g., compare runs 1 to 42 and 46, 14 to 43, or 21 to 47 ) always leads to a weaker $v_{\text {Max }}$ and to a stronger inner shelf flushing (more negative $\psi_{S}$ ). The weaker $v_{\text {Max }}$ is consistent with the notion that tidal rectification is expected to oppose the wind-driven alongshore rectification by tending to generate a negative alongshore mean flow (e.g., Huthnance 1973; Loder 1980; Maas and Zimmerman 1989).

The center of the nearshore rectification consistently occurs at the edge of the inner shelf. Specifically, for the 29 model runs with no mean wind stress, no surface heat flux, and a clearly defined inner shelf $\psi$ minimum, the cross-shelf location of the minimum falls near the edge of the inner shelf (as defined by the Richardson number):

$$
x\left(\psi_{S}\right)=1.05 x_{I S}
$$


where 1.05 is obtained by least-squares fit, the correlation is 0.87 , and the standard deviation of the fit is $3.2 \mathrm{~km}$. For comparison, the $x$ location of $v_{\text {Max }}$ is always greater than $x_{I S}$, typically by $3-12 \mathrm{~km}$.

Model results are clearly sensitive to the surface heat flux. When there is cooling at the surface (runs 48 and 50 vs. run 1 ) or warming (run 49 vs. 1 ), the inner shelf $\left(\psi_{S}\right)$ rectified cell disappears or weakens dramatically relative to the case with no surface heating. The positive rectified mean alongshore flow $v_{\text {Max }}$ is strengthened by an order of magnitude (compared with $0.015 \mathrm{~m} / \mathrm{sec}$ with $Q=0$ ) for all runs with a surface heat flux, regardless of sign (runs $48-50$ vs. 1). This is so even though the imposed heat fluxes are relatively moderate: $O\left(2 \times 10^{-5}{ }^{\circ} \mathrm{m} \mathrm{sec}^{-1} \approx 82 \mathrm{~W} \mathrm{~m}^{-2}\right)$. Interestingly, including a heat flux greatly decreases the sensitivity of $v_{\text {Max }}$ to initial conditions, i.e., the sign of $\tau_{A}$ (runs 48 and 49 compared with 51 and 52). These results thus clearly show that surface heat fluxes can strongly affect both the density-driven rectification and the Castelao et al. (2010) rectification.

Even weak steady alongshore wind stresses (runs 36-40 compared with run 1) strongly affect the mean flow patterns. For example, a steady wind stress of $-0.001 \mathrm{~N} \mathrm{~m}^{-2}$ is enough to eliminate the positive mean alongshore flow, and a steady stress of $0.001 \mathrm{~N} \mathrm{~m}^{-2}$ more than doubles the peak mean alongshore velocity: 0.04 vs. $0.015 \mathrm{~m} \mathrm{sec}^{-1}$ ). Similarly, the mean rectified cross-shelf flow on the inner shelf is also sensitive to the steady wind stress. Because realistic ocean conditions generally include a mean wind stress and a nonzero surface heat flux, one must be wary about applying the present model rectification results to the actual ocean.

\section{Inner shelf and boundary layer processes}

A very idealized one-dimensional steady model is useful for explaining the qualitative mean cross-shelf flow structure in the inner shelf and in the surface and bottom boundary layers. To proceed, the vertical eddy viscosity in the upper ocean is idealized as a step-like structure

$$
\begin{array}{ll}
D=A & \text { for } z \geq-\delta_{M} \\
D=0 & \text { for } z<-\delta_{M}
\end{array}
$$

where $A$ is a constant and $\delta_{M}$ is the boundary layer thickness. Note that $\delta_{M}$ is an arbitrary layer thickness (which can be identified with the surface mixed layer thickness) and need not be the Ekman scale depth. The actual eddy viscosity structure (Fig. 3) is a good deal smoother than (9), but, in either case, the larger values are indeed confined to the boundary layers.

Consider a linear, steady problem for flow in the surface boundary layer, where there is a steady cross-shelf pressure gradient due to a fixed density field in the form

$$
p_{x}=a+b z
$$


where $a$ and $b$ are locally constant, accounting for the pressure gradient associated with free surface tilt and with a vertically uniform horizontal density gradient, respectively. The model neglects any tendency for resulting cross-shelf flows to modify the density, hence pressure field. The modified Ekman layer problem is then

$$
\begin{aligned}
-f<v> & =-\rho_{0}^{-1} p_{x}+D<u>_{z z} \\
f<u> & =D<v>_{z z}
\end{aligned}
$$

with no time-mean surface stress

$$
<u>_{z}=<v>_{z}=0 \text { at } z=0 .
$$

The deeper boundary condition depends on whether the surface boundary layer encounters a solid bottom (the inner shelf problem):

$$
<u>=<v>=0 \text { at } z=-h \text { if } \delta_{M} \geq h,
$$

or an underlying, inviscid interior (the mixed layer problem):

$$
<u>_{z}=\left\langle v>_{z}=0 \text { at } z=-\delta_{M} \text { if } h>\delta_{M} .\right.
$$

An idealization very similar to (11) and (12b) is used by Chen and Chen (2017) to understand wind-driven secondary circulations in an alongshore buoyancy current. The solutions to problems (12b) and (12c) are straightforward and both have the form

$$
<u>+i<v>=d_{1} \exp [(1+i) \varphi z]+d_{2} \exp [-(1+i) \varphi z]+i\left(\rho_{0} f\right)^{-1}(a+b z)
$$

where

$$
\varphi=\left(1 / 2 f A^{-1}\right)^{1 / 2}
$$

In either case, (11b) can be integrated through the layer to find that

$$
f \int^{0}<u>d z=-<\tau_{B}^{y}>\rho_{0}^{-1}
$$

where $\left\langle\tau_{B}^{y}>\right.$ is the alongshore stress at the bottom of the layer (and is not the stress against the bottom of the ocean if Eq. 12c applies) and the lower limit of the integral is either $-h$ if $\delta_{M} \geq h$ or $-\delta_{M}$ if $\delta_{M}<h$. Thus, for a surface mixed layer that does not contact the bottom (12c), there can be no net Eulerian cross-shelf transport in the boundary layer.

For the inner shelf problem (boundary condition $12 \mathrm{~b}$ ),

$$
d_{2}=d_{1}+\frac{i b}{\rho_{0} f(1+i) \varphi}
$$


and

$$
d_{1}=\frac{-i}{2 \rho_{0} f}\left\{\frac{b \exp [(1+i) \varphi h]}{(1+i) \varphi}+a-b h\right\}\{\cosh [(1+i) \varphi h]\}^{-1} .
$$

For this solution as stated, the depth-integrated Eulerian cross-shelf transport need not be zero (14), because the bottom stress is not necessarily equal to zero. Yet, because the problem is two dimensional, this total transport must equal zero. However, one can find an $(a, b)$ combination (i.e., find a cross-shelf pressure gradient field) that is consistent with the twodimensional constraint. For example, for $f=1 \times 10^{-4} \mathrm{sec}^{-1}, \delta_{M}=h=20 \mathrm{~m}, A=0.008$ $\mathrm{m}^{2} \mathrm{sec}^{-1}$, the choice $b=a \times 0.12 \mathrm{~m}^{-1}$ leads to zero net volume transport. For this choice, the baroclinic pressure gradient (associated with $b$ ) is opposed to the sense of the free surface tilt. This outcome is intuitive in that, in a strongly frictional layer, flow is generally down the pressure gradient, and so balancing near-surface and near-bottom transports would call for a reversal with depth in the sign of the pressure gradient (Fig. 9, left panel). That is to say that density increases (temperature decreases) offshore over the inner shelf and thus the downward free surface tilt is neutralized in the lower part of the water column. However, if $b=0$, there is no such zero-transport solution with finite boundary layer thickness $\delta_{M}$ (or finite $A$ ).

At first glance, it might seem improbable that nature would pick a density field that is "just right" with regard to preserving a steady two-dimensional flow field on the inner shelf. However, it is clear that, in this model, the flow field is forced to be two-dimensional (i.e., have nearly zero net Eulerian cross-shelf transport), and that, at the earliest phases, the density field must evolve with time. It thus seems sensible that the density field and surface height would coevolve toward a steady state that has no depth-integrated cross-shelf flow. Although this analytical model is obviously too simple to describe results for a case with realistic mixing, it does seem qualitatively to describe the role of the inner shelf density gradient found in the rectification studied by Castelao et al. (2010) or summarized by $\psi_{S}$ here.

For the mixed layer problem (12c; Fig. 9, right panel) where there is no mean stress acting on the layer,

$$
d_{2}=d_{1}+\frac{i b}{\rho_{0} f(1+i) \varphi}
$$

and

$$
d_{1}=\frac{i b}{2 \rho_{0} f \varphi(1+i)}\left\{1-\exp \left[(1+i) \varphi \delta_{M}\right]\right\}\left\{\sinh \left[(1+i) \varphi \delta_{M}\right]\right\}^{-1} .
$$

In this case, Eqs. (11b), (12a), and (12c) can be combined (or Eq. 14 used) to demonstrate that there is no net cross-shelf Eulerian transport regardless of the values of $a$ and $b$, a result consistent with the absence of any time-mean stress on the upper water column. The fact 

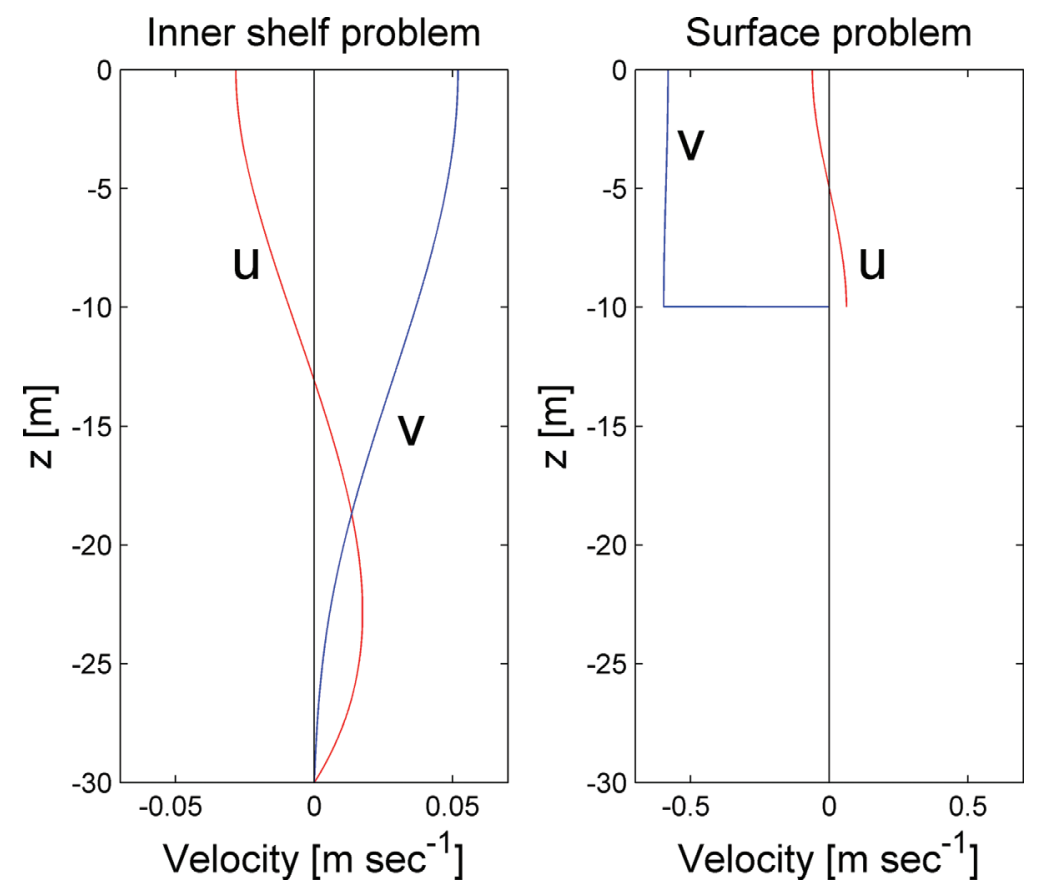

Figure 9. Representative simplified model results for an "inner shelf" case, where $\delta_{M}=h$ (left panel, Eq. 15), and a mixed layer problem, where $\delta_{M}<h$ (right panel). In both cases, $f=1 \times 10^{-4}$ $\mathrm{sec}^{-1}, A=0.008 \mathrm{~m}^{2} \mathrm{sec}^{-1}$, and $h=30 \mathrm{~m}$. Note the differences in horizontal scale. For the left panel, $\delta_{M}=30 \mathrm{~m}, a=1 \times 10^{-5} \mathrm{~N} \mathrm{~m}^{-3}$, and $b=6 \times 10^{-9} \mathrm{~N} \mathrm{~m}^{-4}$. For the right panel, $\delta_{M}=10 \mathrm{~m}, a=1 \times 10^{-6} \mathrm{~N} \mathrm{~m}^{-3}$, and $b=1.2 \times 10^{-7} \mathrm{~N} \mathrm{~m}^{-4}$.

that $d_{1}$ and $d_{2}$ are nonzero, however, points out that there can still be cross-shelf velocities within the boundary layer as long as the horizontal density gradient (i.e., as long as $b$ ) is nonzero. The same logic applies to the bottom boundary layer in the absence of a time-mean alongshore bottom stress, as expected if the mean flow is to reach steady state. This follows because in a steady linear two-dimensional model, surface stress must equal bottom stress everywhere, and the mean surface stress is zero. Thus, circulation cells within the surface and bottom boundary layers (as in Fig. 2, offshore of $x=7 \mathrm{~km}$ ) are not unexpected.

The model is meant to apply to well-mixed turbulent boundary layers, where strong vertical mixing can cancel out lateral advection of density within the boundary layer when the depth-integrated cross-shelf flow is zero, i.e., because the waters are vertically homogeneous, offshore-flowing and onshore-flowing water parcels have the same temperature (or tracer concentration). Because the depth-integrated flow is zero, there is no net crossshelf advection. For both cases treated here, the depth-integrated flow in the turbulent layer indeed vanishes. Thus, it seems that rectified flow in the layer will contribute little to net offshore tracer transports. 


\section{Positive mean alongshore flows}

Regardless of the sign of $\tau_{A}$, the near-bottom temperature field eventually adjusts so that colder water extends up the slope and isotherms at the top of the bottom boundary layer roughly tend to parallel the bottom, although the cross-shelf density gradient within the boundary layer remains (e.g., Fig. 2). This state is qualitatively consistent with the final state found in problems with bottom boundary layer buoyancy arrest (e.g., Brink and Lentz 2010a). The difference between results for the two cases $\left(\tau_{A}>0\right.$ or $<0$; Fig. 6 ) is evidently just a matter of the differing initial responses of the near-bottom density field.

An estimate for the maximum mean alongshore velocity $\left(v_{\text {Max }}\right)$ is found by assuming that the 20-day average mean alongshore flow is in thermal wind balance throughout the water column and that the mean upslope displacement $\Delta x$ of near-bottom isotherms is proportional to the excursion during a single forcing cycle, i.e., to the Ekman transport $\tau_{B} /\left(\rho_{0} f\right)$ divided by the boundary layer thickness $\delta_{B}$ and by the frequency. This yields

$$
\Delta x \approx m\left|\tau_{B}\right|\left(\rho_{0} f \delta_{B} \omega\right)^{-1}
$$

where $m$ is an unknown constant of proportionality and $\delta_{B}$ is the thickness of the bottom boundary layer, taken to be

$$
\delta_{B}=u_{B^{*}}(f N)^{1 / 2}
$$

(a constant of proportionality in Eq. 18 has been deleted because its role is absorbed in $m$ below) where $u_{B^{*}}$ is the friction velocity associated with the fluctuating bottom stress $\tau_{B}$, assumed to be of the magnitude of the fluctuating surface stress so that

$$
u_{B^{*}} \approx\left(\left|\tau_{A}\right| \rho_{0}^{-1}\right)^{1 / 2}
$$

Because the density gradient parallel to the bottom is $\rho_{x^{\prime}}=\alpha \rho_{I z}$ (where $x^{\prime}$ is the cross-shelf coordinate rotated into a frame so that $x^{\prime}$ is parallel to the sloping bottom; e.g., Brink and Lentz 2010a), the density contrast across the top of the bottom boundary layer is then

$$
\Delta \rho=\Delta x \rho_{x^{\prime}}=\rho_{x^{\prime}} m\left|\tau_{B}\right|\left(\rho_{0} f \delta_{B} \omega\right)^{-1}=m \alpha \rho_{I z}\left(u^{*} \omega^{-1}\right)\left(N_{0} f^{-1}\right)^{1 / 2} .
$$

Finally, assuming the top of the bottom boundary layer is a density interface parallel to the bottom, and estimating the shear across a Margules front, the mean interior velocity is expected to be proportional to

$$
\ll v_{\text {Max }} \gg=c u_{B^{*}} S N_{0}\left(N_{0} f^{-1}\right)^{1 / 2} \omega^{-1}
$$

where

$$
s=\alpha N_{0} f^{-1}
$$




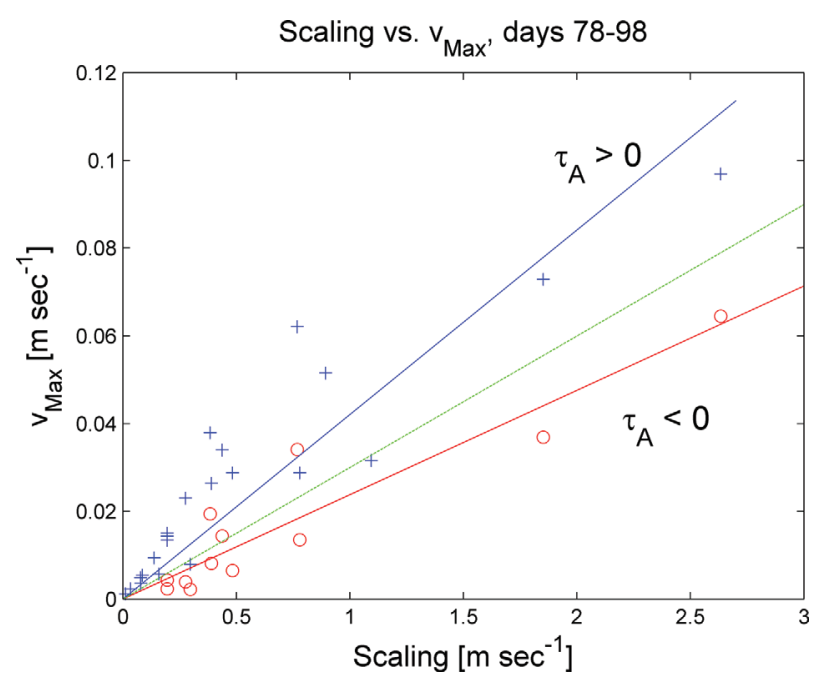

Figure 10. Application of the scaling (21) for maximum mean alongshore velocity in the absence of mean winds or surface heat fluxes. Blue crosses: runs with $\tau_{A}>0$. Red circles: runs with $\tau_{A}<0$. Solid lines represent least-squares fits. The dashed green line is the regression fit for the $\tau_{A}>0$ runs repeated with a 20-day ramp applied to minimize the importance of the initial response.

and the double brackets $\ll \gg$ indicate an estimate and $c$ is an empirical constant (which absorbs $m$ ) found by comparison with model results. Because the mean upslope excursion is expected to be less than the instantaneous range over a cycle, one expects that $c \ll 1$. Further, because of the asymmetry depending on the sign of $\tau_{A}$, different values of $c$ are expected depending on the sign of $\tau_{A}$. Note that the parameter dependences in (21) are generally consistent with results described in Figure 7 or Section 3d (above).

The result (21) is consistent with results from the buoyancy arrest literature (e.g., Brink and Lentz 2010b) in that the bottom boundary layer becomes denser as a result of the bottom boundary layer's response to fluctuating alongshore interior flow. In both cases, this occurs because the more rapid upslope Ekman velocity leads to a net near-bottom transport of dense water toward the coast. Further, one can note that Brink and Lentz (2010b)'s expression for the rectified flow within the capped bottom boundary layer (Equation 39 in Brink and Lentz $2010 \mathrm{~b}$ ) is similar in form (for small $\omega$ ) to the present (21). One would not expect identical expressions, partly because of the differing interior mean velocity (which is identically zero in Brink and Lentz 2010b) and partly because of differing assumptions about the frequency.

For $\tau_{A}>0$, (21) is evaluated with 22 runs having no mean wind stress or surface heat flux (Fig. 10). In this case, $c=0.0014$, the correlation of the fit is 0.88 and the standard deviation of the fit is $0.0142 \mathrm{~m} \mathrm{sec}^{-1}$. For $\tau_{A}<0,(21)$ is evaluated with 12 runs having no mean wind stress or surface heat flux. In this case, $c=0.00081$, the correlation of the fit is 0.91 and the standard deviation of the fit is $0.0078 \mathrm{~m} \mathrm{sec}^{-1}$. If $c$ is estimated using 
$v_{\text {Max }}$ from days 478-498, the $c$ values for $\tau_{A}>0$ and $\tau_{A}<0$ become 0.0076 and 0.0066 , respectively: the discrepancy tied to the initial wind direction decreases, but has still not vanished. Results discussed in Section $3 \mathrm{c}$ and d, however, suggest the discrepancy between the $\tau_{A}>0$ and $\tau_{A}<0$ cases is much weaker when forcing is ramped up gradually or under realistic conditions with a nonzero surface heat flux. Indeed, when the $22 \tau_{A}>0$ runs (with no mean wind or surface heat flux) are repeated with a 20-day ramp-up, (21) yields $c=0.0010$ (correlation 0.89 , error of $0.0095 \mathrm{~m} \mathrm{sec}^{-1}$ ), a value between the previous two unramped $\tau_{A}>0$ and $\tau_{A}<0$ estimates. All considered, 0.0010 should be taken as the most realistic estimate for $c$.

\section{Discussion}

Two varieties of rectified Eulerian flow over a stratified continental shelf are described and explored: one involving an inner shelf cross-shelf circulation cell (described by $\psi_{S}$ ) and another involving a mean alongshore flow in the direction opposite to coastal-trapped wave propagation (described by $v_{\text {Max }}$ ). Both classes of rectification are associated with the existence of stratification over the shelf. Both types of rectification appear clearly in numerical model calculations, but neither has been directly observed in nature. Indeed, numerical experiments here that include either a mean wind stress or a nonzero surface heat flux suggest that the existence of these rectifications might be easily masked, eliminated, or distorted in the real ocean. Indeed, a steady alongshore wind stress of $0.05 \mathrm{~N} \mathrm{~m}^{-2}$ will generate cross-shelf velocities in a surface boundary layer that are about an order of magnitude stronger than those predicted here. In addition, integrated over the thickness of the boundary layer, the cross-shelf transport will be nonzero when the surface boundary layer does not touch the bottom. Further, the calculation of Kuebel-Cervantes, Allen, and Samelson (2004) makes it clear that the Stokes drift is similar in magnitude to the Eulerian means discussed here. The substantial differences for mean alongshore flow depending on the sign of $\tau_{A}$ very likely vanish in a realistic context with surface heat fluxes and without a sharply defined starting condition, as strongly suggested by model runs in which the forcing is applied gradually. All told, it seems likely that the rectified cross-shelf flow modeled here will be weak, hence difficult to observe, and that it will not contribute much to overall cross-shelf tracer transports because of the reversing (with depth) velocities in the presence of strong vertical mixing. The rectified alongshore flow, although not terribly large $(0.1$ $\mathrm{m} \mathrm{sec}^{-1}$ in the strongest simple example here: number 21 ), is much more likely to be observable than the predicted mean cross-shelf flows, which are less than, often much less than, about $0.01 \mathrm{~m} \mathrm{sec}^{-1}$ in the present examples.

Thus, the sensitivity of the present results to surface heating or steady wind stresses suggests that the flow patterns examined here will not be readily observable in nature. However, there are a few lessons to be had from this study. One is that the cross-shelf density gradient on the inner shelf can be important for determining cross-shelf flow. Second, as a consequence, surface heat fluxes can play a substantial role in determining the flow across 
the inner shelf. Third, reasonable surface heating or steady alongshore wind stress can act to mitigate the artificial sensitivity to the initial wind stress. Surface heating and cooling, in a vertically well-mixed region with a sloping bottom, give rise to a cross-shelf temperature gradient, hence contribute to the cross-shelf pressure gradient. It is thus perhaps not too surprising that the surface heat flux plays such an effective role.

Acknowledgments. Discussions with Steve Lentz, along with two helpful reviews, are appreciated. This research was partially supported by the National Science Foundation Physical Oceanography Program through grant OCE-1433953.

\section{REFERENCES}

Allen, J. S. and P. A. Newberger. 1996. Downwelling circulation on the Oregon continental shelf. Part I: response to idealized forcing. J. Phys. Oceanogr., 26, 2011-2035. doi: 10.1175/15200485(1996)026<2011:DCOTOC >2.0.CO;2

Austin, J. A. and S. J. Lentz, 2002. The inner shelf response to wind-driven upwelling and downwelling. J. Phys. Oceanogr., 32, 2171-2193.

Brink, K. H. 2010. Topographic rectification in a forced, dissipative, barotropic ocean. J. Mar. Res., 68, 337-368. doi: 10.1357/002224010794657209

Brink, K. H. and S. J. Lentz. 2010a. Buoyancy arrest and bottom Ekman transport. Part I: steady flow. J. Phys. Oceanogr., 40, 621-635. doi: 10.1175/2009JPO4266.1

Brink, K. H. and S. J. Lentz. 2010b. Buoyancy arrest and bottom Ekman transport. Part II: oscillating flow. J. Phys. Oceanogr., 40, 636-655. doi: 10.1175/2009JPO4267.1

Brink, K. H. and H. Seo. 2016. Continental shelf baroclinic instability. Part II: oscillating wind forcing. J. Phys. Oceanogr., 46, 569-582. doi: 10.1175/JPO-D-15-0048.1

Castelao, R., R. Chant, S. Glenn, and O. Schofeld. 2010. The effects of tides and oscillatory winds on the subtidal inner-shelf cross-shelf circulation. J. Phys. Oceanogr., 40, 775-788. doi: 10.1175/2009JPO4273.1

Chen, S.-Y. and S.-N. Chen. 2017. Generation of upwelling circulation under downwelling winfavorable wind within bottom-attached, buoyant coastal currents. J. Phys. Oceanogr., 47, 24992519.

Garrett, C. J. R. and J. W. Loder. 1981. Dynamical aspects of shallow sea fronts. Phil. Trans. R. Soc. Lond. A, 302, 563-581. doi: 10.1098/rsta.1981.0183

Garrett, C. J. R., P. MacCready, and P. Rhines. 1993. Boundary mixing and arrested Ekman layers: rotating stratified flow near a sloping boundary. Annu. Rev. Fluid Mech., 25, 291-323. doi: 10.1146/annurev.fl.25.010193.001451

Haidvogel, D. B., H. G. Arango, K. Hedstrom, A. Beckmann, P. Malanotte-Rizzoli, and A. F. Shchepetkin. 2000. Model evaluation experiments in the North Atlantic Basin: simulations in nonlinear terrain-following coordinates. Dyn. Atmos. Oceans, 32 239-281. doi: 10.1016/S03770265(00)00049-X

Huthnance, J. M. 1973. Tidal current asymmetries over the Norfolk Sandbanks. Estuar. Coast. Mar. Sci., 1, 89-99. doi: 10.1016/0302-3524(73)90061-3

Kuebel-Cervantes, B. T., J. S. Allen, and R. M. Samelson. 2004. Lagrangian characteristics of continental shelf flows forced by periodic wind stress. Nonlinear Process. Geophys., 11, 3-16. doi: 10.5194/npg-11-3-2004

Loder, J. W. 1980. Topographic rectification of tidal currents on the sides of Georges Bank. J. Phys. Oceanogr., 10, 1399-1416. doi: 10.1175/1520-0485(1980)010<1399:TROTCO>2.0.CO;2 
Maas, L. R. M and J. T. F. Zimmerman. 1989. Tide-topography interactions in a stratified shelf sea II. Bottom trapped internal tides and baroclinic residual currents. Geophys. Astrophys. Fluid Dyn., 45, 37-69.

Phillips, O. M., J.-H Shyu, and H. Salmun. 1986. An experiment on boundary mixing: mean circulation and transport rates. J. Fluid Mech., 173, 473-499. doi: 10.1017/S0022112086001234

Pollard, R. T, P. B. Rhines, and R. O. R. Y. Thompson. 1973. The deepening of the wind-mixed layer. J. Geophys. Fluid Dyn., 3, 381-404. doi: 10.1080/03091927208236105

Wijesekera, H. W., J. S. Allen, and P. Newberger, 2003. A modeling study of turbulent mixing over the continental shelf: comparison of turbulent closure schemes. J. Geophys. Res., 108, 3103. doi:10.1029/2001JC001234

Received: 00 Month xxxx; revised: 00 Month xxxx. 